\title{
Jetted mixtures of particle suspensions and resins
}

\author{
S.D. Hoath ${ }^{1 a}$, T.R. Tuladhar ${ }^{2}$, W.-K. Hsiao ${ }^{1}$, and I.M. Hutchings ${ }^{1}$ \\ ${ }^{1}$ University of Cambridge, Department of Engineering, Institute for Manufacturing, \\ 17 Charles Babbage Road, Cambridge CB3 OFS, UK \\ ${ }^{2}$ Trijet Ltd, 59 Eland Way, Cambridge CB1 9XQ, UK
}

Drop-on-demand (DoD) ink-jetting of hard particle suspensions with volume fraction $\Phi \sim 0.25$ has been surveyed using 1000 ultra-high speed videos as a function of particle size $\left(\mathrm{d}_{90}=0.8-3.6 \mu \mathrm{m}\right)$, with added $2 \mathrm{wt} \%$ acrylic $(250 \mathrm{kDa})$ or $0.5 \mathrm{wt} \%$ cellulose $(370 \mathrm{kDa})$ resin, and also compared with Newtonian analogues. Jet break-off times from $80 \mu \mathrm{m}$ diameter nozzles were insensitive $(120 \pm 10 \mu \mathrm{s})$ to particle size, and resin jet break-off times were not significantly altered by $>30 \mathrm{wt} \%$ added particles. Different particle size grades can be jetted equally well in practice, while resin content effectively controls DoD break-off times.

Many materials applications are being implemented using additive manufacturing, in particular using digital processes such as drop-on-demand (DoD) inkjet printing. Reliable inkjet printing of colloids, and hard particle suspensions such as ceramics, is desirable for modern manufacturing processes. There has been much prior effort to understand ceramic inkjet printing by Evans and co-workers ${ }^{1-3}$, and more recent work by the groups of Chartier ${ }^{4}$, and of Ebert ${ }^{5}$ (using thermal DoD printers), and by Derby ${ }^{6}$. Other experimental work focussed on possible effects of particles on inkjet drop impingement ${ }^{7}$ and on deposition and drying ${ }^{8-10}$, has been published or presented. In the present study the aim is to examine fluid jetting rather than these processes.

Perhaps surprisingly, there are still many unresolved aspects of fluid behaviour under DoD conditions. Weakly elastic polymer solutions "matched" by rheological methods were shown recently to have different jetting speed and break-off behaviour. ${ }^{11}$ As a result of such issues, inkjet processes and fluids design can be rather laborious and successful printing is by no means guaranteed for new applications. Nevertheless recent progress has been reported ${ }^{12-16}$ for the understanding of polymeric fluid jetting rules very relevant to additives that are commonly used either as viscosity modifiers or to form part of the deposition layer, for example in flexible organic electronics.

\footnotetext{
a Author to who correspondence should be addressed.
} Electronic mail: $\underline{\text { sdh35@cam.ac.uk }}$ 
The deposition of hard particles such as inorganic pigments is of increasing interest for larger scale decorative applications ${ }^{17}$, but is currently restricted to relatively small particle $\left(\mathrm{d}_{90} \sim 1 \mu \mathrm{m}\right)$ sizes. Close packed spheres have a maximum occupied volume of $\sim 64$ vol\%. The rheology for model suspensions of spherical polystyrene particles ${ }^{18}$ is well-described by the Zarraga model ${ }^{19} \eta(\varphi)=\eta_{0} \exp (-2.34 \varphi) /\left(1-\varphi / \varphi_{\mathrm{m}}\right)^{3}$ where $\eta_{0}$ is the base fluid viscosity ( $200 \mathrm{mPa} \mathrm{s}$ ) and the maximum volume fraction is $\varphi_{\mathrm{m}}=0.62$. However the base fluid viscosity in DoD inkjet applications is only $\sim 5 \mathrm{mPa}$, very much lower than that used in liquid bridge and dripping experiments with particles, and jetted particle loadings are limited to $35 \mathrm{wt} \%$, for which the corresponding volume fraction $\Phi$ is typically $0.20-0.30$ (but still well beyond the Einstein regime). Recent numerical modelling of liquid bridge ${ }^{20}$ and the prior experimental work on the dripping of liquids containing particles ${ }^{18,21}$ suggest that DoD break-off times could be significantly lowered (by typically $>10 \%$ ) for particle loadings with $\Phi>0.20$.

We report on the influence of hard particle size on the DoD jetting of complex liquids containing particles and/or resins observed using ultra-high speed imaging techniques. A Shimadzu HPV-1 ultra-high speed camera and 500W flash lamp recorded single jets at a rate of 500,000 frames per second for 102 frames of $0.5 \mu$ s exposure time in conventional shadowgraph mode. Offline calibrations with a ruled grating determined that the $312 \times 260$ pixel image scale was $1.7 \mu \mathrm{m} /$ pixel. Off-line image analyses were used to determine jet and drop speeds, while jet break-off times $( \pm 3 \mu \mathrm{s})$ were deduced from the elapsed time between images displaying emergence of the jet tip from the nozzle and the later separation of the jet body from the remaining liquid meniscus ${ }^{22}$.

Liquid jets and main (leading) drops in DoD inkjet printing have speeds and volumes that appear to vary almost linearly with print head drive voltage ${ }^{3,23,24}$ (above a threshold value of drive voltage that depends on viscosity), principally as a result of inertia and the duration of the drive pulse needed to propel the liquid through the nozzle $^{24}$. The DoD jetting threshold drive voltage is empirically determined in the present work by downwards extrapolation from speeds above $1 \mathrm{~m} / \mathrm{s}$ measured at higher drive voltages rather than from lower drive voltages (where surface tension is significant). The speed-drive curve for the jetted solvent has a gradient that seems representative of weakly elastic polymer solutions, shear thinning fluids and colloidal suspensions, and which also appears to be relatively insensitive to the effective jetting viscosity of these complex fluids ${ }^{24}$.

Increased loadings can disproportionately increase the required print head drive to jet the fluid. Suspension viscosity $\eta(\Phi)$ increases non-linearly with increasing $\Phi$ (or vol\%), ${ }^{25}$ and must always exceed Einstein's value $\eta(\Phi)=\eta_{\mathrm{s}}[1+(5 / 2) \Phi]$ for low concentrations of non-interacting spheres in a Newtonian solvent with viscosity $\eta_{\mathrm{s}}$. The Einstein result predicts that suspension rheology will be Newtonian, i.e. independent of shear rate, and also independent of the particle size ${ }^{25}$. As DoD inkjet printing is known ${ }^{22}$ to involve extreme shear rates reaching $10^{6} \mathrm{rad} / \mathrm{s}$, jetting of (hard) particle-laden liquids could be significantly influenced by any deviation from Newtonian behaviour.

Some empirically useful criteria or benchmarks for comparison of results for jetting particle-laden (and resinous) liquids from the same DoD nozzle are (i) the break-off time, (ii) the threshold drive voltage, and (iii) the gradient of the speed-drive curve. These criteria were used in the present work to help judge whether particle size at 
$35 \mathrm{wt} \%$ loading, or $\sim 1 \mathrm{wt} \%$ resin content, controls the observed jetting behaviour. Accurate measurements of jetted drop volumes ${ }^{3,23,26-28}$ (another jetting benchmark) were not available from the high speed imaging experiments that are reported here.

All the particle suspensions were prepared at $35 \mathrm{wt} \%$ in the low viscosity $\left(\eta_{\mathrm{s}}=3.7\right.$ $\mathrm{mPa}$ ) low $(0.148 \mathrm{kDa})$ molecular weight solvent dipropylene glycol methyl ether (DPM). Hard particles were selected with 5 different $\mathrm{d}_{90}$ size grades $(0.8 \mu \mathrm{m}, 1.0 \mu \mathrm{m}$, $1.6 \mu \mathrm{m}, 2.6 \mu \mathrm{m}$ and $3.6 \mu \mathrm{m}$ ) after grinding the same batch of copper chromite black spinel pigment produced by high temperature calcination (Shepherd, USA) with 10 wt\% of an active polymeric dispersant (with MW $<20 \mathrm{kDa}$ ) in an in-house ball grinding mill. Particle size distributions for these 5 selected fluids were fully characterised and the $10 \mathrm{wt} \%$ dispersant in DPM was found to be Newtonian with a viscosity of $6 \mathrm{mPa}$. A Newtonian analogue fluid with viscosity of 10-15 mPa s was later prepared from $85 \mathrm{wt} \%$ ethylene glycol $15 \mathrm{wt} \%$ water for comparison purposes.

Resins of different chemical structures and molecular weights - hydroxyl propyl cellulose at $370 \mathrm{kDa}$ (Ashland, USA) and acrylic at $250 \mathrm{kDa}$ (Evonik Industries, Germany) - were dissolved in DPM solvent and jetted at several concentrations and also jetted in combination with the particle-laden suspensions. This is the first report on jetting of particle suspensions with polymers.

The solutions were manually agitated before decanting into small $(3 \mathrm{~mL})$ reservoirs for jetting from $80 \mu \mathrm{m}$ diameter MicroFab AB print head nozzles. Specific print head drive waveform timings were maintained for all comparisons, with the drive voltage suitably adjusted for jetting. A continuous $100 \mathrm{~Hz}$ printing regime (except during manually triggered video recording) was used to avoid unwanted nozzle clogging. DPM solvent purges of the print head were used to eliminate any cross-contamination between the jetted fluids. At intermediate levels of particle loading, or with poorly mixed fluids, visualisation of particles within the jets could be observed.

Table 1 lists the properties of the particle-laden and resinous fluids jetted in this work.

Table 1. Properties of the resinous and pigmented fluids jetted in the present work

\begin{tabular}{|l|l|l|l|l|l|}
\hline DPM fluid + & $\begin{array}{l}\text { Density } \\
\left(\mathrm{kg} / \mathrm{m}^{3}\right)\end{array}$ & $\begin{array}{l}\text { Surface } \\
\text { tension } \\
(\mathrm{mN} / \mathrm{m})\end{array}$ & $\begin{array}{l}\text { Viscosity } \\
(\mathrm{mPa})\end{array}$ & $\begin{array}{l}\text { Particles } \\
(\mathrm{wt} \%)\end{array}$ & $\begin{array}{l}\text { Particles } \\
(\mathrm{vol} \%)\end{array}$ \\
\hline- & 948 & 29 & 3.7 & - & - \\
\hline $370 \mathrm{kDa}$ cellulose resin & 1000 & 29 & - & - & - \\
\hline $250 \mathrm{kDa}$ acrylic resin & 1000 & 29 & - & - & - \\
\hline $\begin{array}{l}\text { Copper chromite black } \\
\text { spinel pigment }\end{array}$ & $\begin{array}{l}1300- \\
1500\end{array}$ & 29 & $14-17$ & 35 & $27 \pm 2$ \\
\hline $\begin{array}{l}\text { Pigment }+0.5 \mathrm{wt} \% \\
370 \mathrm{kDa} \text { cellulose resin }\end{array}$ & 1000 & 29 & 30 & 31.5 & $24 \pm 2$ \\
\hline $\begin{array}{l}\text { Pigment }+2.0 \mathrm{wt} \% \\
250 \mathrm{kDa} \text { acrylic resin }\end{array}$ & 1000 & 29 & 40 & 31.5 & $24 \pm 2$ \\
\hline
\end{tabular}

The particles vol\% determined from the particles wt $\%$ correspond to the nominal pigment particle density: $\operatorname{vol} \%=100 \Phi=100 /\left\{1+(\{100-\mathrm{wt} \%\} / \mathrm{wt} \%) *\left(\rho_{\text {particle }} / \rho_{\mathrm{DPM}}\right)\right\}$. 
Thus all the particle-loaded inkjet fluids jetted should have volume fraction $\Phi>0.20$. The measured shear viscosities of the dispersed particle fluids appear consistent with those predicted on the Zarraga model ${ }^{19}$ with the parameters quoted by Bonnoit et al ${ }^{18}$.

At 5-20 wt\% concentrations of the resins in DPM, the liquid jets did not emerge from the nozzle exit. At lower concentrations (e.g. $1 \mathrm{wt} \% 370 \mathrm{kDa}$ cellulose and $4 \mathrm{wt} \% 250$ $\mathrm{kDa}$ acrylic), the resin jets emerged but did not break-off from the body of liquid but retracted back into the nozzle after the end of the DoD actuation waveform. Such typical behaviour ${ }^{16}$ shows that the addition (or unwanted presence) of sufficient high (100's kDa) molecular weight polymer to most liquids can significantly limit the DoD jet speed. Further dilutions of the resins were jetted for comparison with the low viscosity Newtonian solvent and the mixed pigment and resin combinations.

Particle size was measured with a Mastersizer 2000 (Malvern Instruments, UK), surface tension with a SITA line T60 bubble tensiometer (Germany) and viscosity with ARES controlled strain rheometer (TA, USA), Bohlin stress controlled coneplate rheometer (Malvern Instruments, UK) and PAV piezo axial vibrator (Germany).

Drop speeds obtained for the DPM solvent, or $35 \mathrm{wt} \%$ particle suspensions of given $\mathrm{d}_{90}$ size, are shown in Figure 1 at various drive voltages for one MicroFab print-head. Comparison of inkjet drop speed versus absolute drive curves between experiments performed with nominally the same fluids jetted by different print heads do require cross-calibrations. Likewise, jetting extrapolated to low drop speed at drive voltages just above 30V for DPM in the same print head but on a different day suggest rather low discrimination was achieved between DPM and pigmented ink jetting in Figure 1.

Additional jetting tests, using $85 \mathrm{wt} \%$ ethylene glycol made up with distilled water to produce a Newtonian analogue liquid with viscosity comparable to that of the $35 \mathrm{wt} \%$ pigments in DPM, had a threshold drive voltage of $\sim 38 \mathrm{~V}$ slightly higher than for these jetted pigments, while, as expected, $1 \mathrm{mPa}$ s distilled water had the lowest $(\sim 26 \mathrm{~V})$ drive threshold. The DoD jetting speed threshold drive voltages are indicated for both on Figure 1, while their speed-drive curves are superposed (after adjustments for the different slope because the additional nozzle differed from the original) for reference.

There was little difference, in the extrapolated drive voltage thresholds or the gradients of the speed-drive curves, between DPM and $35 \mathrm{wt} \%$ particulate liquids. Comparison with the $10-15 \mathrm{mPa}$ s Newtonian analogue fluid drive threshold suggests either (a) filtration action, or (b) shear-thinning, occurs within the jet nozzle. At the relatively low particle loadings $\Phi=0.25$ in the present study, self-filtration effects such as investigated around $\Phi=0.58$ by Morris and co-workers ${ }^{29}$ are probably negligible.

Particle-loaded jets may occasionally exhibit inhomogeneous regions of transparent solvent, moving within the flow, but our ultra-high speed video images revealed far lower than expected particle density in ligaments in only one instance (for $1.6 \mu \mathrm{m}$ ). We have tried to estimate whether the images can be used to establish concentration. The videos showed dark "particle" regions moving along the axis of the jet ligament at an estimated equivalent volume fraction of only $0.2 \mathrm{wt} \%$ (not the bulk $25 \mathrm{wt} \%$ ); a "nearly black" ligament axis (with one transparent image pixel visible) corresponds to $2 \mathrm{wt} \%$ whereas a "fully black" ligament axis is about $100 \mathrm{wt} \%$ (i.e. bulk $25 \mathrm{wt} \%$ ). 
Thus the ultra-high speed camera image analysis provided a rather poor sensitivity at the high particle concentrations of interest, and we cannot rule out filtration action. Alternatively, low densities of particle can help determine fluidic flows within DoD jet ligaments during the thinning and stretching, and will be reported elsewhere.

We now consider shear-thinning, option (b) above. Had these pigmented inks attained a viscosity as low as $3.7 \mathrm{mPa}$ s DPM, the $35 \mathrm{wt} \%$ suspensions would have to have to shear-thin under DoD printing conditions by up to a factor of 3 in effective jetting viscosity compared with their low shear-rate values. However, the minimum viscosity ought to be the Einstein value corresponding to $\Phi$, so the dispersed particle fluid viscosity satisfies $\eta \geq 6(1+0.25 * 5 / 2)=10 \pm 1 \mathrm{mPa}$ s and the maximum possible shear thinning effect is a factor of 1.4-1.7 in viscosity, i.e. barely consistent with Figure 1.

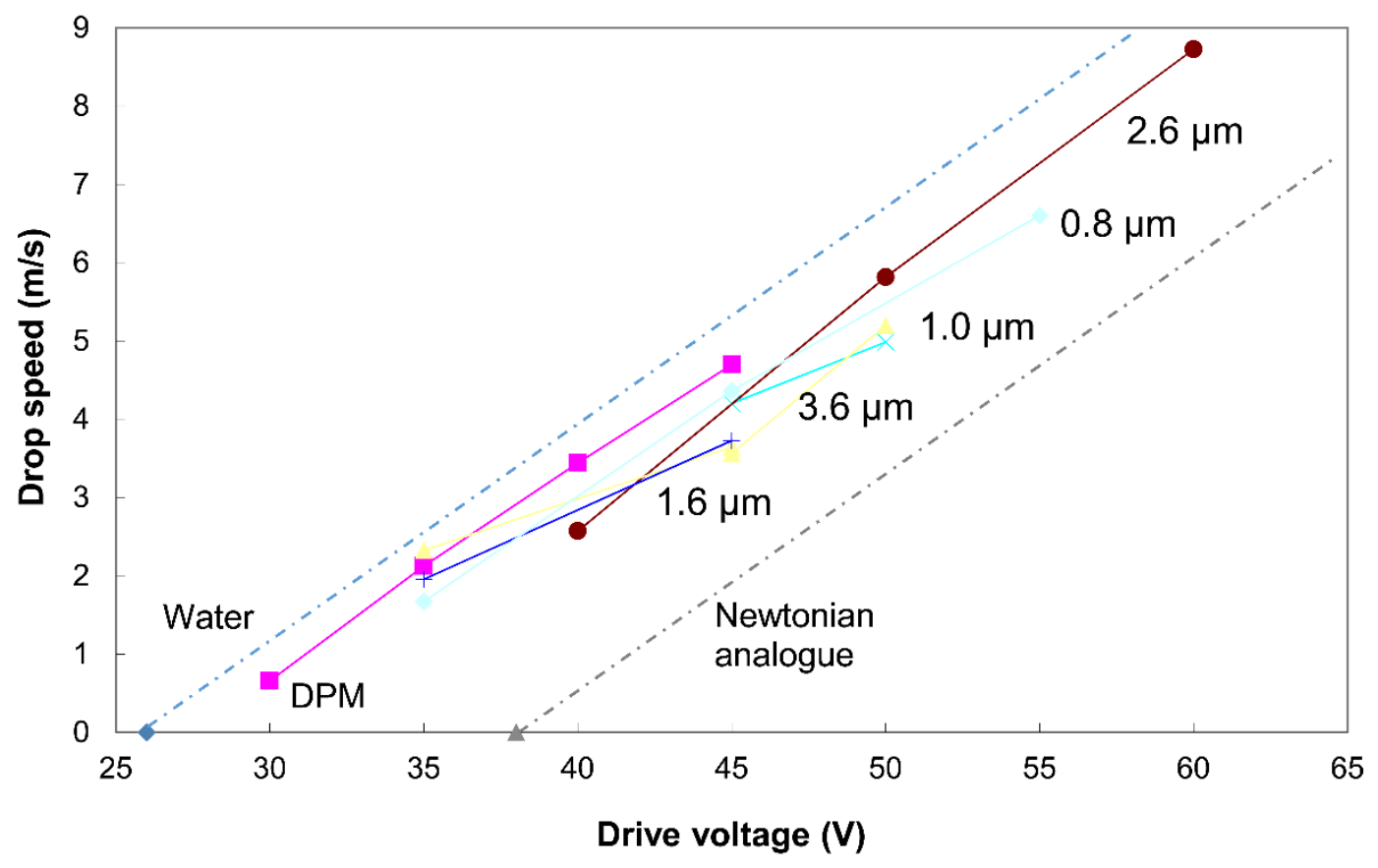

Figure 1 shows the drop speed $(\mathrm{m} / \mathrm{s})$ for jetted DPM and $35 \mathrm{wt} \%$ particle suspensions against the applied drive voltage (V) applied to the MicroFab AB $80 \mu \mathrm{m}$ print-head. The straight lines connect the speeds found at different drive voltage for each $d_{90}$ size. Threshold drive voltages for water (26V) and a Newtonian analogue $85 \mathrm{wt} \%$ ethylene glycol 15 wt $\%$ water solution (38V) shown with adjusted speed-drive curve slopes superposed as broken lines for comparison purposes with the resin jetting. (See text.)

Figure 2 shows jet break-off times for $35 \mathrm{wt} \%$ suspensions at each particle $\mathrm{d}_{90}$ size. All are similar to DPM and the differences between particle sizes appear random. The largest variation in break-off times was for the $1.6 \mu \mathrm{m}$ size, perhaps corresponding to the observation of rather low $1.6 \mu \mathrm{m}$ particle densities in jet ligaments during testing. The average break-off time for jetted DPM was $116 \pm 3 \mu \mathrm{s}$, similar to the average break-off time of $127 \pm 9 \mu \mathrm{s}$ for DPM $+35 \mathrm{wt} \%$ particle independent of pigment size. Addition of $35 \mathrm{wt} \%$ hard particles has (perhaps) slightly increased the size-averaged jet break-off time, but no consistent or strong size dependence is apparent in Figure 2. 


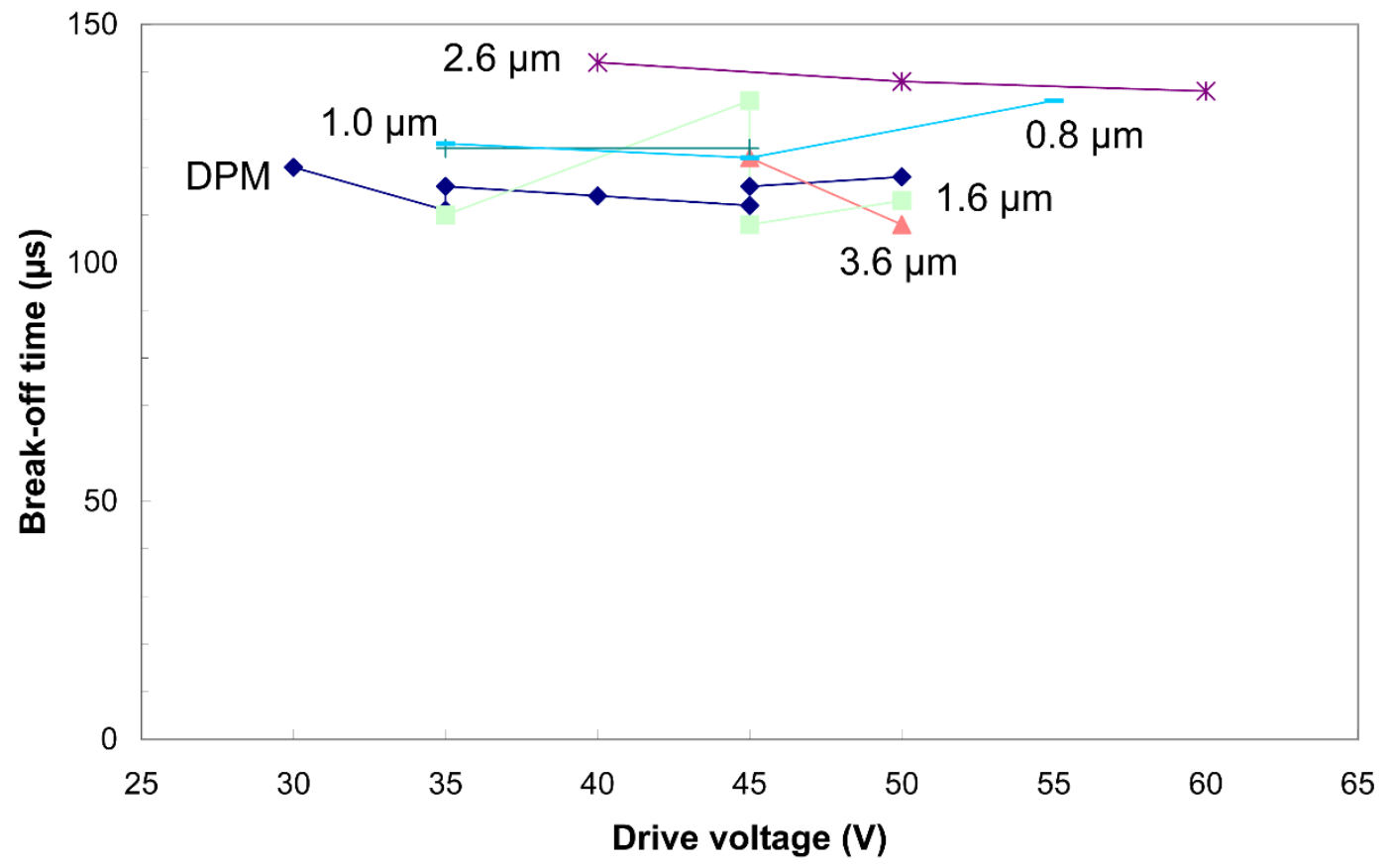

Figure 2. Jet break-off times for DPM and $35 \mathrm{wt} \%$ suspensions of indicated $d_{90}$ size, as a function of the applied drive voltage. The break-off data correspond to Figure 1.

Break-off times of $121 \pm 2 \mu$ s and $122 \pm 2 \mu$ s were recorded for Newtonian $78-85 \mathrm{wt} \%$ ethylene glycol with distilled water (jetted as comparisons) but not shown in Figure 2. The break-off time for $6 \mathrm{mPa}$ s $10 \mathrm{wt} \%$ active polymer dispersant in DPM is expected to be intermediate between the $3.7 \mathrm{mPa}$ s DPM and 10-15 mPa s Newtonian solutions, which themselves differed by only $5 \pm 4 \mu \mathrm{s}$. The $35 \mathrm{wt} \%$ fluid break-off time exceeds the comparison Newtonian fluid break-off time by less than $20 \mu$ s (for $\mathrm{d}_{90}=2.6 \mu \mathrm{m}$ ).

McIlroy and Harlen predict break-off times for particulate liquid bridges with $\Phi=0.20$ would be lowered by about $10 \%$ of the bulk particulate fluid break-off time ${ }^{20}$. Should the model be applicable to jets then the observed particle size-averaged break-off time would correspond to a bulk liquid break-off time of $(127 \pm 9 \mu \mathrm{s}) / 0.9=141 \pm 10 \mu \mathrm{s}$. The decrease of DoD jet break-off time arising from the particle content of the liquid (rather than raised viscosity) would be only $14 \pm 10 \mu$ s in these experiments, far too small to be distinguished in practice, so present data cannot test the simulation results.

Shear-thinning fluids were not considered in the simulations and therefore predictions of $10 \%$ reduced break-off times for $\Phi=0.20$ may not be relevant to these experiments; likewise, the previous dripping experiments and simulations used far larger particles. However the order $1 \mu \mathrm{m}$ particle sizes used in the present work are sufficiently large in comparison with thinning filament diameters that they ought to influence break-off.

Figure 3 shows the results for jet break-off time $(\mu \mathrm{s})$ when suspensions with particles of specific $d_{90}$ size $(\mu \mathrm{m})$ in DPM were jetted from $80 \mu \mathrm{m}$ MicroFab AB nozzles. The error bars show the experimental scatter of results obtained at different jetting speed for jetted DPM with $35 \mathrm{wt} \%$ particles, DPM with $31.5 \mathrm{wt} \%$ particles and $0.5 \mathrm{wt} \%$ $370 \mathrm{kDa}$ cellulose and DPM with $31.5 \mathrm{wt} \%$ particles and $2.0 \mathrm{wt} \% 250 \mathrm{kDa}$ acrylic. 


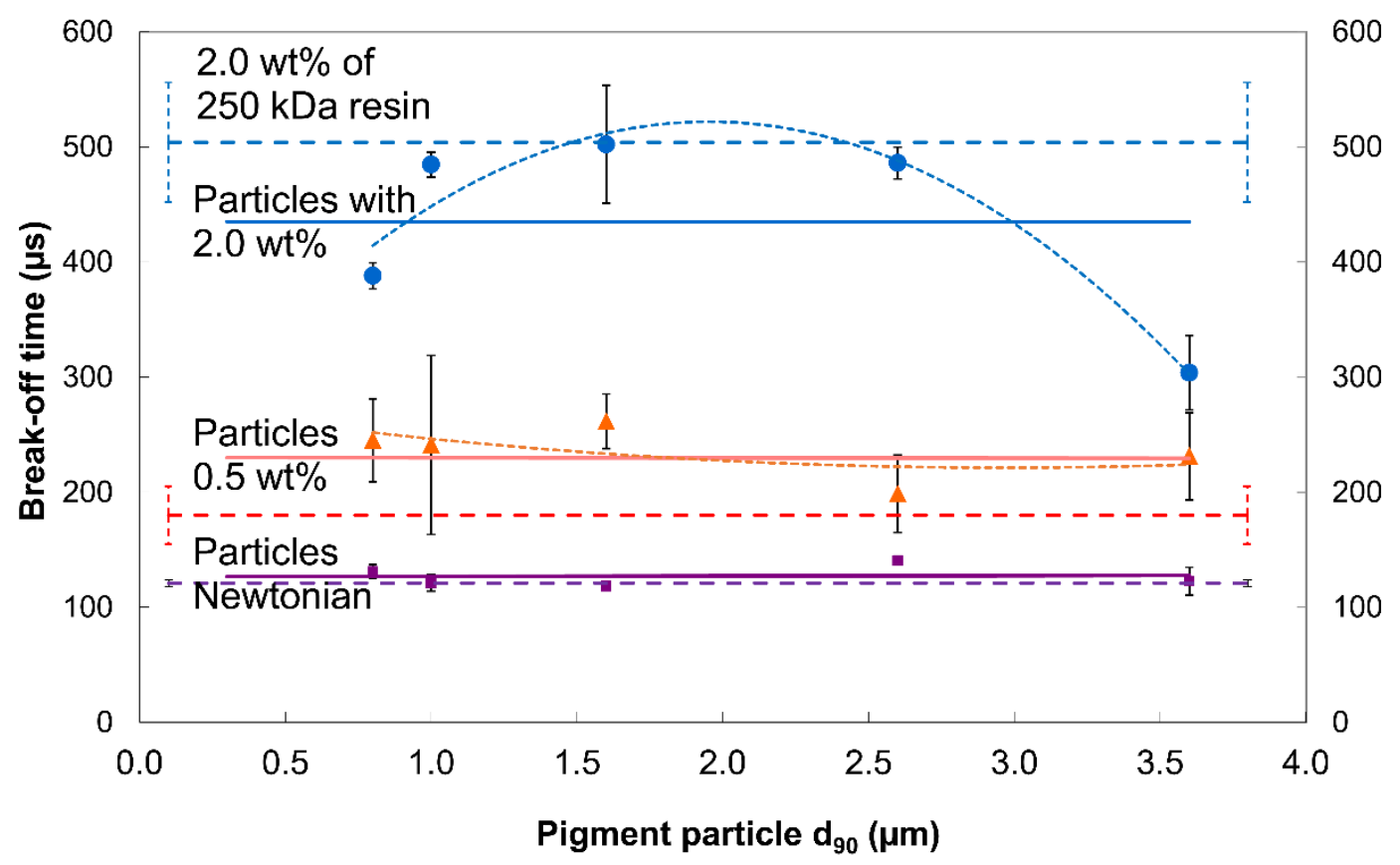

Figure 3. Break-off time ( $\mu$ s) for jetted suspensions of specific particle $d_{90}$ size $(\mu \mathrm{m})$ in DPM: Particles only at 35 wt\%; Particles (at $31.5 w t \%)+0.5 w t \% 370 \mathrm{kDa}$ cellulose resin; Particles (at $31.5 w t \%)+2.0 w t \% 250 \mathrm{kDa}$ acrylic resin. (See text.)

Solid horizontal lines shown in Figure 3 represent the measured break-off times averaged over drive voltages (e.g. Figure 2) for particle suspensions with either no added resin, with $0.5 \mathrm{wt} \% 370 \mathrm{kDa}$ cellulose resin or with $2.0 \mathrm{wt} \% 250 \mathrm{kDa}$ acrylic resin. Approximately 1000 videos at 500,000 fps were analysed in this survey of particle effects on jetting. The number of repeated observations was however far too low to examine the variance of break-off times. The error bars shown reflect the range of average break-off times that were observed in the video recordings for each jetted fluid - where these error bars are relatively small, the break-off behaviour was very repeatable as the drive voltage was altered. Typically, each fluid variant was recorded 5-20 times. The uppermost solid straight line does not fit the data well, as shown by the quadratic fit, but since the break-off times for the extremes of particle size are both lower to the same degree in terms of their uncertainty ranges, no linear trend of break-off time with particle size was determined in the present work.

Addition of resin to the particle formulations significantly increased the jet break-off times despite reducing the overall particle content to $31.5 \mathrm{wt} \%$. Particles in DPM jets had break-off times of $236 \pm 23 \mu$ s with added $0.5 \mathrm{wt} \% 370 \mathrm{kDa}$ cellulose and $433 \pm$ $85 \mu \mathrm{s}$ with $2.0 \mathrm{wt} \% 250 \mathrm{kDa}$ acrylic resin. The particle-laden resin jet break-off time increased roughly in proportion to the wt $\%$ resin content, after accounting for a scale factor of 2.0 in relaxation times associated with the molecular weight of the cellulose resin compared with that of the acrylic resin using Zimm power law relationships ${ }^{13}$. This evidence suggests that the addition of $35 \mathrm{wt} \%$ of hard particles to either resin type has not influenced the resin jetting: polymer jetting was discussed elsewhere ${ }^{12}$.

The influence of $35 \mathrm{wt} \%$ of added particles on the break-off times for the resins was also assessed using data from separate jetting studies of particle-free resin. Results from these extra studies are superposed on Figure 3 as dashed lines with error bars. 
The alteration of the resin break off time caused by the addition of $31.5 \mathrm{wt} \%$ particles was an additional $56 \pm 34 \mu \mathrm{s}$ for the $0.5 \mathrm{wt} \% 370 \mathrm{kDa}$ cellulose resin and a reduction by $71 \pm 100 \mu$ s for the $2 \mathrm{wt} \% 250 \mathrm{kDa}$ acrylic resin. Inspection of Figure 3 shows that the reduction in the latter is completely eliminated if the break-off times for the largest and smallest particle sizes are treated as outliers. Even without this, two-tailed statistical tests showed that these break-off time differences cannot rule out the null hypothesis that adding the particles to the resin will cause no change in the resin break-off times.

Although the resin types mixed with particles Figure 3 differed, their low frequency viscosity values (shown in Table 1) were similar, and reduce by a factor of 2 at $5 \mathrm{kHz}$ as determined by a piezo axial vibrator (PAV) device ${ }^{30}$. Previous work on inkjet fluid has suggested that using high frequency rather than zero shear-rate characterisation was helpful in inkjet printing applications because of the high shear-rates (typically $500 \mathrm{kHz}$ from the Newtonian value of 8U/D for drop speed U and drop diameter D) experienced at the DoD nozzle walls. The $35 \mathrm{wt} \%$ particulate fluids may also slightly shear-thin during the DoD jetting process, as implied by the lowered drive threshold compared with $85 \mathrm{wt} \%$ glycerol15 wt $\%$ water of $10-15 \mathrm{mPa}$ s Newtonian viscosity.

Calculations readily show that capillary break-off in the dripping experiments occurs in the large Ohnesorge number Oh regime but in jetting Oh $<1$, where $\mathrm{Oh}=\eta / \sqrt{ }(\rho \sigma \mathrm{R})$ for viscosity $\eta$, density $\rho$, surface tension $\sigma$ and nozzle radius $R$. The simulations of McIlroy and Harlen ${ }^{20}$ suggest that the same particle accelerated break-up appears in both regimes, but the effect on break-off time is admittedly small on the $80 \mu \mathrm{m}$ scale. Fast filament stretching experiments on the $1.2 \mathrm{~mm}$ scale are reported elsewhere $\mathrm{s}^{31-33}$.

The present results suggest that DoD jetting of particle-laden fluids behave as Newtonian fluid, albeit at a slightly shear-thinned viscosity in comparison with low shear-rate values, with very little influence of particle $d_{90}$ sizes for jetting nozzle exit diameters 20 times larger. The apparent lack of sensitivity to particle size may reflect the uncertainties arising from other practical considerations and the inherent time variation in break-off phenomena associated with jetting and/or dripping processes. Resin additives provided the usual level of control by increasing jet break-off times, although the variations in break-off times also increased with the wt $\%$ resin content.

No attempt has been made in the present work to optimise the DoD waveform to minimise the drop volume or jet break-off time, as would be done for applications. This first study of jetting of model particle and resin combinations has continued interest for applications, in particular for the jetting and rheology of industrial inks and the development of new fluid testing hardware reported elsewhere ${ }^{31-33}$. The recent simulations suggest further experimental jetting work to determine the dependence of the variance of break-off times on particle concentration, particle size, resin content and type would be needed to test and establish physical explanations of the current observations. Nevertheless the implications of the present work for inkjet applications is a lot clearer: DoD jetting of hard particle fluids does not depend on particle size, and the jet break-off time can be controlled using low $(<1 \mathrm{wt} \%)$ high MW resins.

This work was supported by the UK Engineering and Physical Sciences Research Council (EPSRC) through grant number EP/H018913/1 (Innovation in Industrial 
Inkjet Technology) and a consortium of UK companies, whose permission to publish and support for this work is acknowledged. Adrian Walker (EPSRC Engineering Instrument Loan Pool) assisted with the Shimadzu HPV-1 high speed camera system and Adept Electronics high power long duration flash lamps used in the present work. SDH acknowledges useful discussions about [20] with Claire McIlroy and several significant improvements to the original manuscript also suggested by the reviewers.

1. P.F. Blazdell, J.R.G. Evans, M.J. Edirisinghe, P. Shaw, and M.J. Binstead, "The computer aided manufacture of ceramics using multilayer jet printing", J. Mater. Sci. Lett. 14, 1562-1565 (1995).

2. M. Mott, J.-H. Song, and J.R.G. Evans, "Microengineering of Ceramics by Direct Ink-Jet Printing”, J. Amer. Ceram. Soc. 82, 1653-1658 (1999).

3. K.A.M. Seerden, N, Reis, J. R.G. Evans, P.S. Grant, J.W. Halloran, and B. Derby, "Ink-Jet Printing of Wax-Based Alumina Suspensions", J. Am. Ceram. Soc., 84 2514-2520 (2001).

4. M. Lejeune, T. Chartier, C. Dossou-Yovo, and R. Noguera, "Ink-jet printing of ceramic micro-pillar arrays", J. Eur. Ceram. Soc. 29, 905-911 (2009).

5. E. Özkol, J. Ebert, and R. Telle, "An experimental analysis of the influence of the ink properties on the drop formation for direct thermal inkjet printing of high solid content aqueous 3Y-TZP suspensions", J. Eur. Ceram. Soc. 30, 1669-1678 (2010).

6. B. Derby, "Inkjet printing ceramics: From drops to solid", J. Eur. Ceram. Soc. 31, 2543-2550 (2011).

7. H. Ok, W.W. Carr, H. Park, and J.F. Morris, "Effects of Particles on drop impingement", IS\&T's NIP20: 2004 International Conference on Digital Printing Technologies (IS\&T, Springfield VA, 2004) pp 612-616.

8. R.D. Deegan, O. Bakajin, T.F. Dupont, G. Huber, S.R. Nagel, and T.A. Witten, "Capillary flow as the cause of ring stains from dried liquid drops", Nature 389, 827-829 (1993).

9. B.-J. de Gans and U.S. Schubert, "Inkjet printing of Well-Defined Polymer Dots and Arrays", Langmuir, 20 7789-7793 (2004).

10. E.L. Talbot, A. Berson, and C.D. Bain, "Drying and Deposition of Picolitre Droplets of Colloidal Suspensions in Binary Solvent Mixtures", NIP28: $28^{\text {th }}$ International Conference on Digital Printing Technologies and Digital Fabrication 2012, The Society for Imaging Science and Technology, (IS\&T, Springfield VA, 2012) pp 420-423, ISSN: 978-0-89208-301-5. ; and "Internal Flows and Particle Transport Inside Picolitre Droplets of Binary Solvent Mixtures", NIP29: $29^{\text {th }}$ International Conference 2013, The Society for Imaging Science and Technology, (IS\&T, Springfield VA, 2013) pp 307-312, ISSN: 978-0-89208-307-7.

11. S.D. Hoath, D.C. Vadillo, O.G. Harlen, C. McIlroy, N.F. Morrison, T.R. Tuladhar, S. Jung, W.-K. Hsiao, G.D. Martin, and I.M. Hutchings, "Ink-jet printing of weakly elastic polymer solutions", J. Non-Newt. Fluid Mech. 205, 1-10 (2014).

12. C. McIlroy, O.G. Harlen, and N.F. Morrison, "Modelling the jetting of dilute polymer solutions in drop-on-demand inkjet printing", J. Non-Newt. Fluid Mech. 201, 17-28 (2013).

13. S.D. Hoath, O.G. Harlen, and I.M. Hutchings, "Jetting behaviour of polymer solutions in drop-on-demand inkjet printing”, J. Rheology 56, 1109-1127 (2012).

14. N.F. Morrison and O.G. Harlen, "Viscoelasticity in inkjet printing", Rheol Acta 49 619-632 (2010). 
15. V. Tirtaatmadja, G.H. McKinley and J.J. Cooper-White, "Drop formation and breakup of low viscosity elastic fluids: Effects of molecular weight and concentration," Phys. Fluids 18, 043101 (2006).

16. A.V. Bazilevskii, J.D. Meyer, and A.N. Rozhkov, "Dynamics and break up of pulsed microjets of polymeric liquids", Fluid Dynamics 40, 376 (2005).

17. I.M. Hutchings, "Impresión por chorro de tinta para la decoración de baldosas: tecnología y oportunidades (II). Tecnica Ceramica, 395. pp. 558-561. ISSN 02117290 (2011).

18. C. Bonnoit, T. Bertrand, E. Clément, and A. Lindner, "Accelerated drop detachment in granular suspensions", Phys. Fluids 24043304 (2012).

19. E. Zarraga, D.A. Hill, and D.T. Leighton, "The characterization of the total stress of concentrated suspensions of non-colloidal spheres in Newtonian fluids," J. Rheol. 44(2), 185-220 (2000).

20. C. McIlroy, and O.G. Harlen, "Modelling capillary breakup of particulate suspensions", Phys. Fluids 26, 033101 (2014).

21. R.J. Furbank, and J.F. Morris, "An experimental study of particle effects on drop formation”, Phys. Fluids 16 1777-1790 (2004).

22. S.D. Hoath, W.-K. Hsiao, S. Jung, J.R. Castrejón-Pita, G.D. Martin, I.M. Hutchings, C. McIlroy, N.F. Morrison, O.G. Harlen, T.R. Tuladhar, D.C. Vadillo, S.A. Butler, M.R. Mackley, and H.N. Yow, "Jetting of complex fluids", J. Imaging Sci. Technol. 57, 040401 (2013).

23. N. Reis, C. Anslie, and B. Derby, "Ink-jet delivery of particle suspensions by piezoelectric droplet ejectors", J. Appl. Phys. 97094903 (2005).

24. S.D. Hoath, W.-K. Hsiao, S. Jung, G.D. Martin, I.M Hutchings, N.F. Morrison, and O.G. Harlen, "Drop speeds from drop-on-demand inkjet print-heads", J. Imaging Sci. Technol. 57, 010503 (2013).

25. C.W. Macosko, "Rheology principles, measurements and applications", WileyVCH (1994).

26. I.M. Hutchings, G.D. Martin, and S.D. Hoath, "High Speed Imaging and Analysis of Jet and Drop Formation”, J. Imaging Sci. Technol. 51, 438-441 (2007).

27. H. Dong, W.W. Carr, and J.F. Morris, "Visualisation of drop-on-demand inkjet: Drop formation and deposition", Rev. Sci. Instrum. 77, 085101 (2006).

28. A. van der Bos, M.-J. van der Meulen, T. Driessen, M. van den Berg, H. Reinten, H. Wijshoff, M. Versluis, and D. Lohse, "Velocity Profile inside Piezoacoustic inkjet droplets in flight: comparison between experiment and numerical simulation", Phys. Rev. Applied 1, 014004 (2014).

29. S.D Kulkarni, B. Metzger, and J.F. Morris, "Particle-pressure-induced selffiltration in concentrated suspensions", Phys. Rev. E 82, 010402(R) (2010).

30. D.C. Vadillo, T.R. Tuladhar, A.C. Mulji, and M.R. Mackley, "The rheological characterization of linear viscoelasticity for ink jet fluids using piezo axial vibrator and torsion resonator rheometers", J. Rheology 54, 781-795 (2010).

31. T.R. Tuladhar and M.R. Mackley, "Filament stretching rheometry and break-up behaviour of low viscosity polymer solutions and inkjet fluids", J. Non-Newtonian Fluid Mech. 148, 97-108 (2008).

32. D.C. Vadillo, T.R. Tuladhar, A.C. Mulji, S. Jung, S.D. Hoath, and M.R. Mackley, "Evaluation of the ink jet fluid's performance using the "Cambridge Trimaster" filament stretch and break-up device", J. Rheology 54, 261-282 (2010).

33. M.R. Mackley, T.R. Tuladhar, S.A. Butler, D.C. Vadillo, S.D. Hoath, and S. Huxley, "Fast filament stretching, thinning and break up", invited talk, British Society of Rheology, Midwinter 2013 meet, Cambridge, unpublished (2013). 